\title{
EGF-receptor signaling and epithelial-mesenchymal transition in human carcinomas
}

\author{
Ala-Eddin Al Moustafa ${ }^{1,2,3}$, Amal Achkhar ${ }^{1,4}$, Amber Yasmeen $^{2}$ \\ ${ }^{I}$ Syrian Research Cancer Centre of the Syrian Society against Cancer, Aleppo, Syria; Oncology Department, Faculty of \\ Medicine, McGill University, Montréal, Canada; Department of Mechanical Engineering, Concordia University, Montréal, \\ Quebec, Canada; ${ }^{4}$ Faculty of Pharmacy, University of Aleppo, Aleppo, Syria
}

\section{TABLE OF CONTENTS}

\author{
1. Abstract \\ 2. Introduction \\ 3. Epidermal growth factor receptor signaling \\ 4. Epithelial-mesenchymal transition and E-cadherin expression \\ 5. Epithelial-mesenchymal transition/Epidermal growth factor receptor interaction \\ 6. Conclusions and Future Perspectives \\ 7. Acknowledgments \\ 8. References
}

\section{ABSTRACT}

The epidermal growth factor receptor (EGF-R) signaling pathway maintains a balance between cell proliferation, differentiation and apoptosis, and thus it is believed that EGF-R signaling pathways play an important role in the development and progression of several human carcinomas. Epithelial-mesenchymal transition (EMT) describes the dedifferentiation switch between polarized epithelial cancer cells and contractile and motile mesenchymal (invasive) cells during cancer progression and metastasis. Activation of EGF-R signaling regulates EMT-associated invasion and migration in normal and malignant epithelial cells. In contrast, blocking EGF-R and consequently its pathways, by a monoclonal antibody $(\mathrm{mAb})$ or a tyrosine kinase inhibitor (TKI), inhibit cellular migration and invasion, suggesting an essential role for EGF-R inhibitors in the control of cancer metastasis. The purpose of this review is to summarize current information regarding the role of EGF-R signaling on EMT during human cancer progression and metastasis.

\section{INTRODUCTION}

Carcinomas are tumors of epithelial origin and represent over $90 \%$ of human cancers; metastatic carcinomas are responsible for the majority of cancerrelated deaths, either directly due to tumor involvement of critical organs or indirectly due to complications of therapy to control tumor growth and spread. The epidermal growth factor receptor (EGF-R) is a receptor tyrosine kinase that is over-expressed in a wide variety of human carcinomas, including non-small cell lung, breast, head and neck, bladder, ovarian and prostate cancer, and it has been associated with a number of studies of advanced disease and poor prognosis $(1,2)$. In addition, it is well known that EGF-R is not only important in cell proliferation, but in a number of varied processes likely to be significant for carcinomas progression such as cell adhesion, cell motility and invasion which are major steps in the epithelialmesenchymal transition (EMT) event $(3,4)$. The EMT is a highly conserved cellular program that allows polarized, immotile epithelial cells to convert to motile mesenchymal 


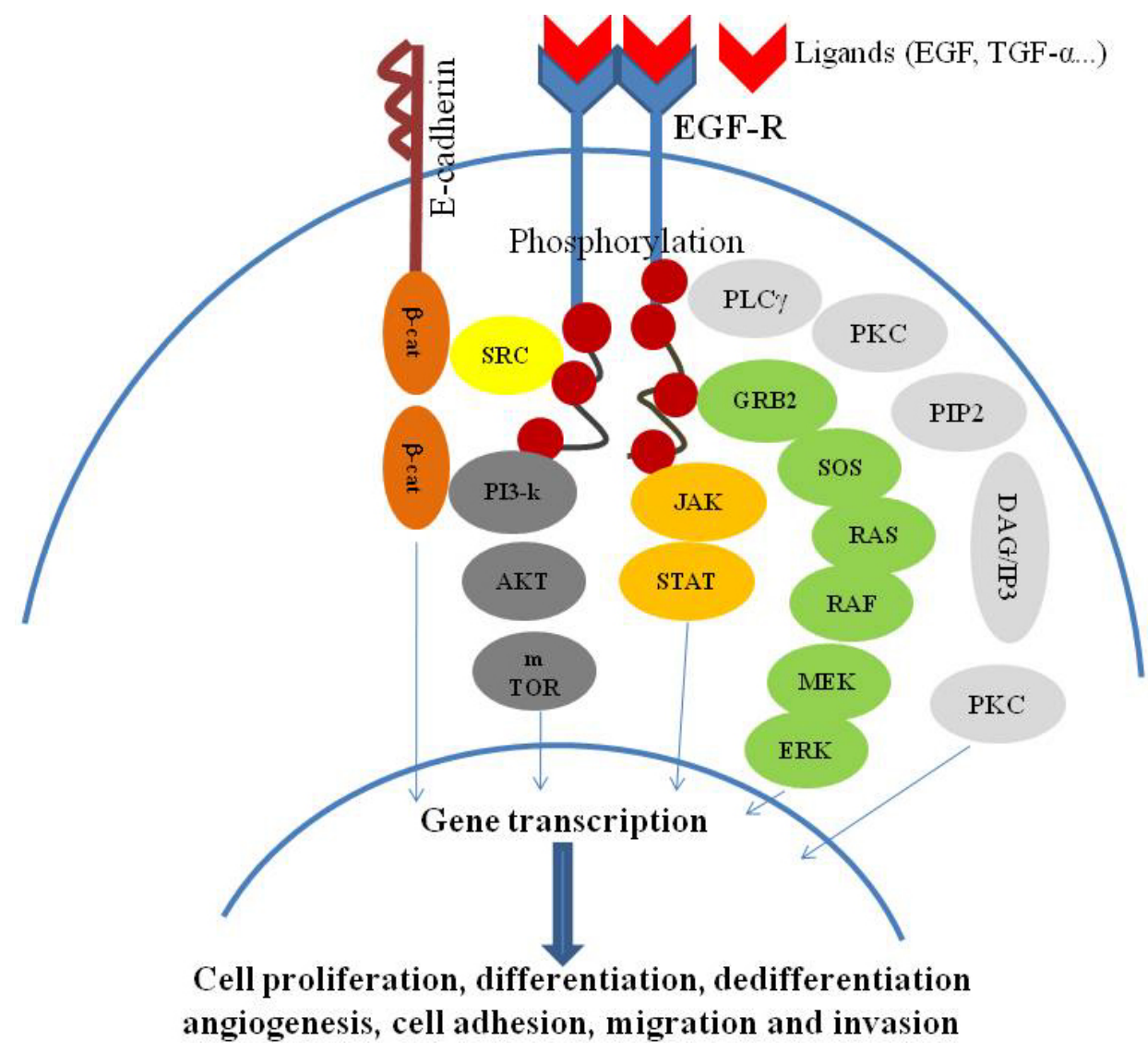

Figure 1. EGF receptor signaling pathways. Ligands of the EGF family bind to the EGF-R and incite homo or heterodimerization that causes phosphorylation of distinct tyrosine residues. Afterwards, the receptor homo or hetero-dimers activate downstream-signaling pathways including JAK, PI3 kinase, SRC kinase, PLCy and the ERK pathway. These pathways ultimately alter the activity of multiple nuclear transcription factors. The EGF-R network initiates diverse cellular mechanisms that lead to cell proliferation, differentiation, dedifferentiation, angiogenesis, cell adhesion, migration and invasion.

cells $(4,5)$. This important process was initially recognized during several critical stages of embryonic development and has more recently been implicated in promoting carcinomas invasion and metastasis. In this review, we discuss the role of EGF-R signaling in human carcinomas progression through its regulation of the EMT process.

\section{EPIDERMAL GROWTH FACTOR RECEPTOR SIGNALING}

The epidermal growth factor receptor (EGF-R) is a 170-kd, 1186-amino acid long transmembrane receptor belonging to a family of receptor tyrosine kinases that includes, in addition to EGF-R, three other members (ErbB2/HER-2, ErbB3/HER-3, and ErbB4/HER-4) (6,7,8). These four receptors share a common structure that is composed of an extracellular domain with binding site for specific ligands, a short transmembrane region, and an intracellular tyrosine kinase domain. A number of ligands can bind to EGF-R such as epidermal growth factor (EGF), heparin-binding EGF-like growth factor (HB-EGF), amphiregulin (AR), betacellulin (BTC) and transforming growth factor-alpha (TGF- $\alpha)(9,10,11,12)$. Binding these ligands to the extracellular domain of the receptor results in receptor conformational changes, which facilitate the receptor homo- or heterodimerization $(13,14)$, followed by autophosphorylation of key tyrosine residues within the $\mathrm{COOH}$-terminal portion of EGF-R, which can act as specific docking sites for specific proteins containing $\mathrm{Src}$ homology 2 and phosphotyrosine binding domains $(15,16,17)$. The activation of EGF-R initiates intracellular signaling via several pathways including Ras/ MAPK, Akt, Src family of kinases, Jak-Stat and the phospholipids metabolism enzymes, phospholipase C-c (PLC- c), phosphatidylinositol 3-kinase (PI3K), and phospholipase D pathways $(15,18,19,20,21)$. The activation of these pathways initiate the transcription of several genes involved in cell proliferation, survival, differentiation, apoptosis and adhesion $(22,23,24,25,26,27,28)$ (Figure 1). More specifically, Ras/MAPK pathway regulates cell proliferation, transformation, and metastasis development, while, the Akt pathway is involved in cell survival processes, apoptosis resistance, invasion and migration $(26,27,29)$. In addition to ligand binding, EGF-R can be activated by phosphorylation of specific amino acid residues as a result of trans-activation by G-protein coupled receptors (30). Phosphorylation of receptor can also occur in response to nonspecific stimuli, including exposure to 
ionizing radiation, UV radiation, hypoxia, hyperthermia and oxidative stress $(31,32,33,34)$. Given the significant role of EGF-R signaling in all aspects of cell growth and survival (Figure 1), the alterations in the function of EGF-R are expected to play a crucial role in the development and progression of some pathological conditions including cancer.

Accumulating evidence supports the key role of EGF-R in the development and progression of many human tumors. For example, EGF-R mutations are found in most of human tumors such as head and neck squamous cell carcinomas (HNSCC), glioblastoma, NSCL, breast, colorectal, bladder, prostate and ovarian carcinomas $(35,36,37,38,39,40,41,42,43)$. A strong correlation has been found between EGF-R mutations and tumor aggressiveness (44), decreased overall survival (45), poor prognosis (46), treatment resistance (47), disease recurrence (48), and increased risk of metastasis $(49,50,51)$. EGF-R abnormalities within detected cancer types include gene amplification (40), protein over-expression and aberrant activation $(51,52,53,54)$. Gene amplification of EGF-R has been shown to especially occur in epithelial cancers, and it was presumed to play a central role in the early pathogenesis and progression of these tumors $(35,40,55,56,57)$. Over-expression of EGF-R has been detected in squamous cell carcinomas and to a lesser extent in adenocarcinomas $(39,58,59)$.

Mutations in the EGF-R kinase domain have been often diagnosed in a number of carcinomas such as HNSCC, colorectal and NSCLC $(38,60,61)$. EGF-R mutations were also reported in atypical adenomatous hyperplasia, which is considered to be a precursor lesion of lung adenocarcinomas $(62,63)$, suggesting that EGF-R mutations are also involved in the early stage of lung cancer progression. Moreover, several studies have shown that mutations in the tyrosine kinase domain of the EGF-R gene strongly correlate with ethnicity $(64,65)$, and the clinical responses to EGF-R inhibitors such as gefitinib $(66,67,68,69)$. The majority of EGF-R mutations occurs in exons $18-21$, the first four exons encoding tyrosine kinase domain, and the most prevalent mutations consist of inframe deletions in exon 19 (45.7\%). Over 20 variant types of mutations have been detected $(70,71)$. The mutation in exon 21, which leads to L858R substitution, accounts for $43 \%$ of EGF-R mutations. Less frequent, point mutations, such as G719C and G719S in exon 18, account for 3.5\% of EGFR mutations. There are occasional in-frame insertion mutations in exon $20(72,73,74)$.

In spite of many proposed hypotheses, the mechanisms of how the mutations affect EGF-R function and what role they play in the oncogenic processes require further investigations. It is proposed that mutations spread along the kinase-coding regions (exons 19-21) result in constitutive autophosphorylation, leading to the stimulation of the basal kinase activity, and thus activation of EGF-R. These mutations also appear to enhance sensitivity to cancer treatment by TKIs (75). It has been hypothesized that EGF-R mutations in cancer cells (deletion in exon 19 and L858R mutation in exon 21) lead to a selective activation of PI3K/Akt and Jak/Stat signaling pathways that inhibit apoptosis and promote cell survival with less effect on the mitogen-activated protein kinase (MAPK) pathway that induces cell proliferation $(76,77)$. In contrast, overexpression of EGF-R in different tissues including urothelium, glial cells or esophageal keratinocytes was found to increase proliferation, migration, and aggregation (78). Deletion of exon 19 appears to confer higher malignant transforming ability than exon 21-point mutation (L858R), and this difference is believed by some researchers to reflect patient survival $(48,79)$. Finally, it has been shown that the EGF-R gene intron 1 has a polymorphic region of $\mathrm{CA}$ dinucleotide repeats, ranging from 9 to 26 repeats, and these repeats are proposed to affect $E G F-R$ transcription efficiency, influence clinical prognosis, and modulate anti-EGF-R drug sensitivity in colorectal, head and neck, lung and breast cancers $(80,81)$. The aforementioned pathways are often associated with the implication of cancer progression in accordance with EGF$\mathrm{R}$ in homo or hetro-dimerization with ErbB family members. Next, we will discuss the critical involvement of EGF-R pathways in human carcinomas progression through its regulation of epithelial-mesenchymal transition phenomena and E-cadherin expression.

\section{EPITHELIAL-MESENCHYMAL TRANSITION AND E-CADHERIN EXPRESSION}

Epithelial-mesenchymal transition (EMT) is an evolutionary conserved developmental process (82) that plays a critical role in the embryonic development, cancer progression and metastasis. It is probable that a common molecular mechanism is shared by these processes $(4,83,84)$. EMT is a multi-step process in which cells acquire molecular alterations that facilitate dysfunctional cell-cell adhesive interactions (4), loss of cell-cell junctions (83) and reorganization of the cytoskeleton (85), all of which result in the loss of apical polarity and the acquisition of a more spindle-shaped morphology $(4,82)$ (Figure 2). Most cancer cells, like epithelial cells during embryonic development, undergo physical and biochemical changes that enable them to interact with the surrounding microenvironment, thus facilitating their migration from the site of origin and dissemination to distant tissues and organs $(4,82)$. Moreover, similar to normal development, epithelial-like cancer cells in the primary tumor can initiate a multi-step process whereby cells down-regulate the expression of intracellular proteins, such as E-cadherin, occludin and claudins and up-regulate signaling pathways and proteins, such as N-cadherin and vimentin (86) associated with a more motile, mesenchymal-like phenotype. Such changes lead to alterations in cell polarity and cell-cell adhesion as the epithelial cells transition to a mesenchymal-like phenotype $(4,87)$. These changes are hallmark feature of EMT (87); this incites to a reduction in cell-cell adhesion and enhances migratory capacity $(4,82,88)$.

Several genes including ErbB family are involved directly and/or indirectly in the initiation of the EMT phenomenon and consequently cancer progression and 


\section{Epithelial - Mesenchymal Transition (EMT)}

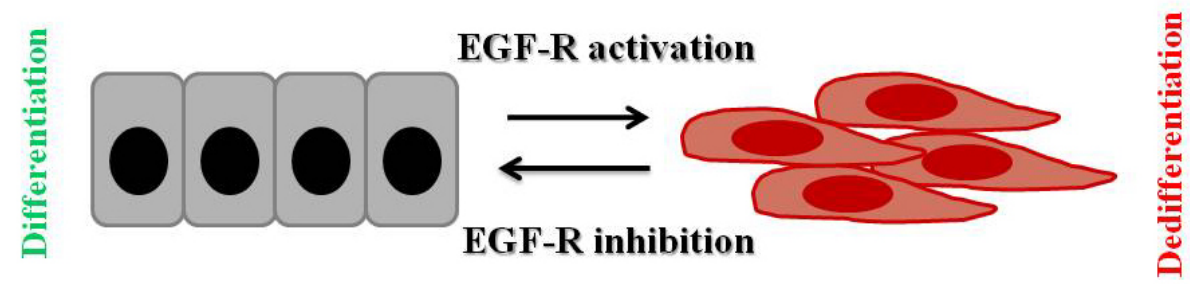

\section{Adherent Immobilized cells}

Invasive cells

Figure 2. Epithelial-mesenchymal transition (EMT) event and EGF-R modulation. The EMT is a multi-step process which allows cells migration and invasion through dysfunctional cell-cell adhesive interactions, loss of cell-cell junctions and reorganization of the cytoskeleton; these procedures result in the loss of apical polarity and the acquisition of a more spindleshaped morphology. Activation of EGF-R induces dedifferentiation EMT which is accompanied by over-expression of mesenchymal markers such as vimentin, fibronectin and N-cadherin. In contrast, EGF-R inhibition, by a TKI or antibody, provokes differentiation MET which is escorted by markers such as E-cadherin and ZO-1.

metastasis. For example, EGF-R activity has been shown to induce tumor cell motility and invasion by regulating the activity of downstream signaling molecules, such as FAK, $\beta$-catenin, Ras, Raf, MAPK, and PI3K/Akt (89). The activation of different pathways including ErbB signaling can result in increased activity of transcriptional repressors, such as Snail, Zeb, and Twist, which repress expression of cell adhesion molecules like E-cadherin (90). On the other hand, EGF-R signaling can induce EMT, invasion, and metastasis in several different types of rodent and human cancer cells including human breast cancer, which can be mediated via STAT3-dependent Twist up-regulation (91) or by inducing the expression of Snail and Zeb $(90,82)$.

The E-cadherin expression in normal cells is thought to stabilize the cell architecture, and as such its expression is an indispensible element of epithelial differentiation (3). More importantly, its reduced expression has been associated with the induction of EMT, which is instrumental in pathologies such as carcinomas invasion $(92,83)$. In addition, earlier studies have described the EMT signature of decreased E-cadherin expression and increased vimentin and $\mathrm{N}$-cadherin expression in mammary gland hyperplasia's and tumors from transgenic mice overexpressing human Cripto-1 (93). An increase in migration and invasion of cervical and breast cancer cells has been associated with Cripto-1 over-expression $(94,95)$. These findings support the significant role of Cripto-1 in the induction of EMT in cancer cells which may explain, in part, why Cripto-1 expression has been associated with more aggressive behavior in several human carcinomas including breast cancer and colon cancer $(95,96)$.

Further, previous studies reported that E-cadherin expression can be regulated by the deregulation of Cox-2 and Pge-2 in human lung carcinomas $(97,98)$. Cox-2 and Pge-2 expression resulted in a significant reduction in Ecadherin via Zeb-1 and Snail transcriptional factor mediated mechanism, and inhibition of Cox-2 resulted in the rescue of E-cadherin expression (97). This newly defined pathway for transcriptional regulation of Ecadherin has important implications on chemoprevention and treatment of human carcinomas especially lung metastatic cancer using Cox-2 inhibitors through the inhibition of EMT progression. Moreover, the ectopic expression of Snail or Slug has resulted in EMT-associated enhanced motility, invasiveness, and tumorigenicity in ovarian cancer cells (99); while, activation of these transcriptional factors by hypoxia revealed immediate upregulation of Slug expression with consequent downregulation of Snail and E-cadherin expression (100) thus stimulating EMT progression. Further evidence of EMT in ovarian cancer is supported by a recent study which demonstrated that $17 \mathrm{~b}$-estradiol increased Snail expression with subsequent increase in the MMP-2 expression and decrease in E-cadherin expression in estrogen receptor positive and estrogen receptor negative ovarian cancer cell lines (101).

The coupled expression of E-cadherin and $\beta$ catenin has been shown to be critical for the stable assembly of a cytoskeleton structure, and maintenance of cell-cell contact in epithelial cells (102). In colon cancer, constitutive activation of the Wnt signaling pathway is a key contributor to tumorigenesis (103). Accumulation of nuclear $\beta$-catenin was observed at the invasive front and in tumor cells migrating into stroma $(104,105)$, consistent with an EMT. In contrast, in the remainder of the primary tumor, and in metastases, heterogeneous intracellular distribution of $\beta$-catenin was detected $(103,106)$.

The role of EMT in prostate cancer progression has emerged from studies using in vitro and in vivo models. Various factors appear to be altered in the prostate cancer microenvironment through increased production of tumor cells or the cancer-associated stroma these changes appear to be associated with EMT (107). Many of these factors have also been shown to cause EMT in other systems (107- 
109). For example, the transcription factor Twist similarly represses E-cadherin expression as well as up-regulates Ncadherin levels in prostate cancer cells $(110,111)$. In contrast, loss of prostate-derived ETS factor (PDEF), which is down-regulated by TGF- $\beta$, induces EMT in PC3 cells (112). In addition, over-expression of prostate specific antigen (PSA) and kallikrein-related peptidase 4 (KLK4), both potential activators of pro-EGF and latent TGF- $\beta 2$, results in EMT in PC3 cells $(113,114)$. On the other hand, PSA and KLK4 which are part of normal prostatic secretions, leak into the tumor microenvironment due to the disruption of glandular architecture during cancer progression, suggesting a link between tissue architecture and EMT.

Earlier study indicates that EMT of tumor cells not only causes increased metastasis, but also contributes to drug resistance (115). This implies that treatments that target cell growth pathways might not be effective in killing these cells. Indeed, increasing amount of data relate drug resistance of tyrosine kinase inhibitors to the existence of EMT. For instance, epithelial but not mesenchymal gene signature has been associated with sensitivity to the small molecule-EGFR-inhibitor erlotinib (Tarceva) (116). Clinical trials confirmed this relationship in several carcinomas; significant benefits were observed in lung carcinoma patients with high expression of E-cadherin who were treated with erlotinib, contrarily to the E-cadherinnegative patients this was also found in xenografts of lung carcinoma cells (117) as well as in other types of tumors such as head and neck squamous cell carcinomas and hepatocellular carcinomas (115). Other EGF-R inhibitors exhibited the same affect, such as gefitinib (Iressa) (118) and cetuximab (119). In parallel, gemcitabine-resistant pancreatic cells with increased invasive capacities, oxaliplatin-resistant colorectal cancer cells and post-ionizing radiation related tumor distant metastasis in patients with advanced lung cancer, have all been associated with EMT (120-122). In addition, an EMT implication in therapeutic drug resistance was recently increased with Lapatinib resistance in breast cancer (123) and paclitaxel resistance in epithelial ovarian carcinomas (124). In fact, empirical reports connecting EMT to the emergence of stem cells has recently been reported (125).

To conclude, progression of human carcinomas involves spatial and temporal occurrences of EMT, whereby tumor cells acquire a more invasive and metastatic phenotype. Subsequently, the disseminated mesenchymal tumor cells must undergo the reverse transition, MET, at the site of metastases, as metastases recapitulate the pathology of their corresponding primary tumors. Initiation of tumor growth at the secondary site is the rate-limiting step in metastasis. This suggests that cellular plasticity and the ability to undergo from EMT to MET in the appropriate microenvironments are key features for a successful cancer treatment (Figure 2). Thus, targeting EMT and/or its regulators may provide a novel strategy to inhibit cancer progression and metastasis by trapping disseminated tumor cells in a state of micro- metastasis.

\section{EPITHELIAL-MESENCHYMAL TRANSITION/EPIDERMAL growth factor receptor interaction}

It is known that epithelial and mesenchymal tissues are endowed with different adhesion systems that have to be modulated in order to allow cells to move. Normal epithelial cells adhere to the basement membrane matrix and to each other by the E-cadherin/catenin complex (3). Mesenchymal cells, that generally do not establish significant cell-cell adhesions, are characterized by dynamic cell-matrix adhesions present on the entire cell surface which allows them to move individually within the ECM (3-5) (Figure 2). In addition to regulating cell-matrix adhesion, EGF-R can also influence cell-cell adhesion. Indeed, there is strong evidence that the altered balance between the two adhesion systems can contribute to invasion and cancer progression $(4,126)$ (Figure 2). It is well documented that EGF-R activation causes disruption of cell-cell junctions and promotion of invasiveness through the phosphorylation of the E-cadherin/catenin complex thus resulting in dissociation of the latter and functional loss of E-cadherin; these events releases $\beta$ catenin into the cytoplasm and then into the nucleus, which stimulates transcriptional activity $(3,127,128,129)$. $\beta$ catenin-regulated genes, such as Myc, Snail-family members, cyclin D1, vimentin, and matrix-degrading proteases, are involved in EMT, invasion and tumor progression $(128,130)$.

In order to investigate the role of EGF-R activation in human lung carcinomas EMT and consequently cell motility and invasion in these cancer cells, we examined the effect of a ligand-blocking mAb against the EGF-R, LA1, in three human lung cancer cell lines H322, A549 and H661 as well as human normal bronchial epithelial (HNBE) cells. We found that the LA1 mAb inhibits cell growth, induces differentiation to a more epithelial phenotype and up-regulates E-cadherin protein expression in H322, A549 and HNBE cells. In contrast, LA1 had no effect on H661 cells, which do not express detectable levels of EGF-R $(3,131,132)$. Furthermore, we investigated the effect of LA1 $\mathrm{mAb}$ on the E-cadherin/catenin complex in H322 and A549 cell lines. Inhibition of EGF-R was associated with re-localization of E-cadherin, $\alpha$-catenin and $\beta$-catenin, but not $\gamma$-catenin. Moreover, we demonstrated that mAb LA1 induces up-regulation of the Ecadherin/catenin complex and inhibits cell motility of both cell lines. In contrast, EGF and HB-EGF lignads induce cell proliferation and the epithelial-like to fibroblastoid (mesenchymal) conversion of H322, A549 and HNBE cells, slightly reduces the expression of E-cadherin and $\beta$ catenin, but not $\alpha$ - and $\gamma$-catenins, and stimulates cell motility $(3,131,132,133)$. More interestingly, we found that amphiregulin, another lignad of EGF-R, stimulates cell proliferation but not the epithelial-like to fibroblastoid conversion of H322, A549 and HNBE cell lines. This is a very important issue for different aspects of human health especially in skin restoration where we can provoke normal epithelial cell proliferation without any modification in their phenotype [Al Moustafa et al., unpublished data]. Nevertheless, these studies demonstrate that EGF-R 
modulation regulates the E-cadherin/catenin complex and consequently cell motility and invasion of human lung carcinoma cells.

In order to develop new strategies in the treatment of human prostate and lung carcinomas, we investigated the effect of Teucrium polium (TP) medicinal plant extract on two human prostate and lung cancer cell lines, PC3 and DU145 and A549 and H322, respectively; we found that TP plant extract inhibits cell proliferation and induces cell apoptosis in these cell lines $(134,135)$. More importantly, we demonstrated that $T P$ plant extract induces differentiation (fibroblast-like to epithelial transition) and blocks cell invasion ability of PC3 and DU145 prostate cancer cells though the restoration of Ecadherin/catenin complex via Src dephosphorylation which is an important pathway of EGF-R activation (134); Our recent results revealed that $T P$ plant extract blocks cell invasion through the inactivation of EGF-R which in turn dephosphorylates Src in human prostate and lung cancer cells (134). Activation of several different cell signaling pathways regulated by EGF-R stimulates the induction of EMT $(136,137)$. Chronic stimulation with EGF can result in activation of Snail and EMT in several human carcinomas including breast $(131,136,138)$. Blocking EGF-R signaling inhibits alcohol-stimulated Snail mRNA expression which play an important role in EMT (139) and Snail mediated colon cancer metastases in mice (140). EMT in cervical cancer is also correlated with EGF-R and Snail over-expression (141). Moreover, cigarette smoke exposure activates EGF-R which can contribute to prolonged downstream signaling through the activation of Akt and extracellular signal regulated kinases (ERK1/2)-survival, proliferation and cell adhesion pathways and consequently the EMT process in human lung cancer $(142,143)$. Meanwhile and as we mentioned above, it has been reported that EMT plays an important role in resistance to EGF-R TKIs, during which cancer cells lose their epithelial marker, such as E-cadherin $(116,117,118)$. In contrast, strong expression of E-cadherin enhances gefitinib sensitivity in lung carcinomas with a mesenchymal phenotype (116). Although EMT can predict resistance to gefitinib or erlotinib $(117,118,144)$, nevertheless the molecular mechanisms are still unknown.

Src kinases are transducers of signals activated by many different classes of cell-surface receptors. More specifically, Src can be activated by growth factor receptors including EGF-R and Met-receptors, cytokine receptors, protein tyrosine phosphatase $1 \mathrm{~B}, \mathrm{CAS}$, and focal adhesion kinase (FAK). Src interacts with a network of intracellular signaling pathways, including the integrin/FAK pathway, $\beta$-catenin/Wnt, RAS-MEK, phosphatidylinositol-3-OH kinase-AKT and Janus-activated kinase-STAT pathways $(145,146,147)$. These complex interactions explain why Src is involved in a large number of cellular functions. In order to determine the role of Src , as an important pathway of EGF-R and a major target in the treatment of several human carcinomas, we examined the effect of $\mathrm{Src} / \mathrm{Abl}$ inhibitor, SKI-606 on cell proliferation, cell cycle progression, mesenchymal-epithelial transition and finally invasion and motility in numerous human carcinoma cell lines including lung, breast and cervical. The Src/Abl inhibitor induces mesenchymal-epithelial transition and consequently up-regulates E-cadherin expression and inhibits cell invasion ability of human lung, breast and cervical cancer cells. This effect occurs through the conversion of $\beta$-catenin's role from a transcription regulator to a cell-cell adhesion molecule via $\mathrm{Src}$ dephosphorylation $(148,149)$. Collectively, these data suggest the concept that EGF-R and/or its pathways inactivation play an important role in the regulation of cell invasion and metastasis of human carcinoma cells through MET (Figure 2). Therefore, EGF-R-targeted therapies using new specific molecule of one and/or two pathways of EGF-R and/or mAbs against EGF-R are important strategies to treat several human carcinoma patients.

\section{SUMMARY AND PERSPECTIVES}

The EMT is a process that plays essential roles in epithelial cancer metastasis that is characterized by loss of homotypic adhesion, cell polarity, increased invasion and migration. On the other hand, the EMT process has provided insight into the mechanisms that are implicated in the migration, invasion, and metastatic spread of cancer cells. Indeed, this review has highlighted the importance of the EGF$\mathrm{R}$ alteration in regulating epithelial plasticity and EMT during human carcinomas progression. Understanding and defining the initial molecular signals leading to the EMT switch in tumor cells would undoubtedly contribute to earliest clinical detection and intervention strategies. Although the use of inhibitors delivered individually to EGF-R targets appears rational, however, limited efficacy suggests that a combinatorial approach would offer improved clinical outcome. Therefore, it should be promising to identify new molecules that selectively target cancer cells via more than one EGF-R pathway. Overall, understanding how EGF-R actuation controls EMT and in particular cancer cell motility should greatly facilitate the design of more successful, personalized cancer therapies.

\section{ACKNOWLEDGMENTS}

We are thankful to Mrs. A. Kassab and Mr. E Segal for their critical reading of the manuscript. The research works from Dr. Al Moustafa's laboratory has been supported by the Canadian Institutes for Health Research, the Cancer Research Society Inc. of Canada, the National Colorectal Cancer Campaign and the Fonds de la Recherche en Santé du Québec (FRSQ- Réseau du Cancer).

\section{REFERENCES}

1. M.V. Grandal \& I.H. Madshus: Epidermal growth factor receptor and cancer: control of oncogenic signalling by endocytosis. J Cell Mol Med 5A,1527-34 (2008)

2. T. Mitsudomi \& Y. Yatabe: Epidermal growth factor receptor in relation to tumor development: EGFR gene and cancer. FEBS J 277, 301-8 (2010)

3. A. Yasmeen, T.A. Bismar \& A-E. Al Moustafa: ErbB receptors and epithelial-cadherin-catenin complex in human carcinomas. Future Oncol 2, 765-81 (2006) 
4. J.P. Thiery, H. Acloque, R.Y. Huang \& M.A. Nieto: Epithelial-mesenchymal transitions in development and disease. Cell 139, 871-90 (2009)

5. D.S. Micalizzi, S.M. Farabaugh \& H.L. Ford: Epithelialmesenchymal transition in cancer: parallels between normal development and tumor progression. J Mammary Gland Biol Neoplasia 2, 117-34 (2010)

6. A. W. Burgess, "EGFR family: structure physiology signalling and therapeutic targets." Growth Factors 26, 263-74 (2008)

7. N. E. Hynes: ErbB2 activation and signal transduction in normal and malignant mammary cells. J Mammary Gland Biol Neoplasia 1, 199-206 (1996)

8. M. Sibilia, R. Kroismayr, R. Kroismayr, B. M. Lichtenberger, A. Natarajan, M. Hecking \& M. Holcmann: The epidermal growth factor receptor: from development to tumorigenesis. Differentiation 75, 770-87 (2007)

9. D. Harari, E. Tzahar, J. Romano, M. Shelly, J. H. Pierce, G. C. Andrews \& Y. Yarden: Neuregulin-4: a novel growth factor that acts through the ErbB-4 receptor tyrosine kinase. Oncogene 18, 2681-2689 (1999)

10. E. Di Marco, J. H. Pierce, T. P. Fleming, M. H. Kraus, C. J. Molloy, S. A. Aaronson \& P. P. Di Fiore, Autocrine interaction between TGF alpha and the EGF-receptor: quantitative requirements for induction of the malignant phenotype. Oncogene 4, 831-838 (1989)

11. K.L. Carraway III, J. L. Weber, M. J. Unger, J. Ledesma, N. Yu, M. Gassmann \& C. Lai: Neuregulin-2, a new ligand of ErbB3/ErbB4- receptor tyrosine kinases. Nature 387, 512-516 (1997)

12. S. J. Fuller, K. Sivarajah \& P. H. Sugden: ErbB receptors, their ligands, and the consequences of their activation and inhibition in the myocardium. $J$ Mol Cell Cardiol 44, 831-54 (2008)

13. B. S. Hendriks, L. K. Opresko, H. S. Wiley \& D. Lauffenburger: Quantitative analysis of HER2-mediated effects on HER2 and epidermal growth factor receptor endocytosis: distribution of homo- and heterodimers depends on relative HER2 levels. J Biol Chem 278, $23343-$ $51(2003)$

14. X. Qian, C.M. LeVea, J.K. Freeman, W.C. Dougall \& M.I. Greene: Heterodimerization of epidermal growth factor receptor and wild-type or kinase-deficient Neu: a mechanism of interreceptor kinase activation and transphosphorylation. Proc Natl Acad Sci US A 91, 1500-4 (1994)

15. A. Chattopadhyay, M. Vecchi, Q. Ji, R. Mernaugh \& G. Carpenter: The role of individual $\mathrm{SH} 2$ domains in mediating association of phospholipase $\mathrm{C}$-gammal with the activated EGF receptor. J Biol Chem 274, 26091-26097 (1999)
16. M. A. Lemmon \& J. Schlessinger: Regulation of signal transduction and signal diversity by receptor oligomerization. Trends Biochem Sci 19, 459-63 (1994)

17. Y. Yarden, \& M.X. Sliwkowski: Untangling the ErbB signalling network. Nat Rev Mol Cell Biol 2, 127-37 (2001)

18. P. Fedi, J.H., Pierce, P.P. di Fiore and M.H. Kraus: Efficient coupling with phosphatidylinositol 3-kinase, but not phospholipase $\mathrm{C}$ gamma or GTPase activating protein, distinguishes ErbB-3 signaling from that of other ErbB/ EGFR family members. Mol Cell Biol 14, 492-500 (1994)

19. R. Marais, \& C.J. Marshall: Control of the ERK MAP kinase cascade by Ras and Raf. Cancer Surv 27: 101-25 (1996)

20. J.K. Voice, R. L. Klemke, A. Le \& J.H. Jackson: Four human ras homologs differ in their abilities to activate Raf-1, induce transformation, and stimulate cell motility. J Biol Chem 274, 17164-70 (1999)

21. L. Simpson \& R. Parsons "PTEN: life as a tumor suppressor. Exp Cell Res 264, 29-41 (2001)

22. T. Jun, O. Gjoerup \& T.M. Roberts: Tangled webs: evidence of cross-talk between c-Raf-1 and Akt. Sci STKE 21, PE1 (1999)

23. E.B. Haura, Z. Zheng, L. Song, A. Cantor \& G. Bepler: Activated epidermal growth factor receptor-Stat3 signaling promotes tumor survival in vivo in non-small cell lung cancer." Clin Cancer Res 11, 8288-94 (2005)

24. C.D. Andl, T. Mizushima, K. Oyama, M. Bowser, H. Nakagawa \& A.K. Rustgi: EGFR-induced cell migration is mediated predominantly by the JAK-STAT pathway in primary esophageal keratinocytes. Am J Physiol Gastrointest Liver Physiol 287, G1227-37 (2004)

25. J. Li, C. Ma, Y. Huang, J. Luo \& C. Huang: Differential requirement of EGF receptor and its tyrosine kinase for AP-1 transactivation induced by EGF and TPA. Oncogene 22, 211-9 (2003)

26. G.A. Repasky, Y. Zhou, S. Morita \& C.J. Der: Rasmediated intestinal epithelial cell transformation requires cyclooxygenase-2-induced prostaglandin E2 signaling. Mol Carcinog 46, 958-70 (2007)

27. M. Toulany, K. Dittmann, B. Fehrenbacher, M. Schaller, M. Baumann \& H.P. Rodemann: PI3K-Akt signaling regulates basal, but MAP-kinase signaling regulates radiation-induced XRCC1 expression in human tumor cells in vitro. DNA Repair (Amst) 7, 17461756 (2008)

28. K.N. Richards, P.A. Zweidler-McKay, N. Van Roy, F. Speleman, J. Trevino, P.E. Zage \& D. P. Hughes: Signaling of ERBB receptor tyrosine kinases promotes neuroblastoma growth in vitro and in vivo. Cancer 116 , $3233-43$ (2010) 
29. A. Citri, K.B. Skaria \& Y. Yarden: The deaf and the dumb: the biology of ErbB-2 and ErbB-3. Exp Cell Res 284, 54-65 (2003)

30. N.E. Bhola \& J.R. Grandis: Crosstalk between Gprotein-coupled receptors and epidermal growth factor receptor in cancer. Front. Biosci 13, 1857-1865 (2008)

31. A. Knebel, H.J. Rahmsdorf, A. Ullrich \& P. Herrlich: Dephosphorylation of receptor tyrosine kinases as target of regulation by radiation, oxidants or alkylating agents. EMBO J 15, 5314-5325 (1996)

32. X.H. Peng, P. Karna, Z. Cao, B.H. Jiang, M. Zhou \& L. Yang: Cross-talk between epidermal growth factor receptor and hypoxia-inducible factor- 1alpha signal pathways increases resistance to apoptosis by up-regulating survivin gene expression. J Biol Chem 281, 25903-25914 (2006)

33. A.L. Evdonin, I.V. Guzhova, B.A. Margulis \& N.D. Medvedeva: Extracellular heat shock protein 70 mediates heat stress-induced epidermal growth factor receptor transactivation in A431 carcinoma cells. FEBS Lett 580, 6674-6678 (2006)

34. E.M. Khan, J.M. Heidinger, M. Levy, M.P. Lisanti, T. Ravid \& T. Goldkorn: Epidermal growth factor receptor exposed to oxidative stress undergoes Src- and caveolin-1dependent perinuclear trafficking. $J$ Biol Chem 281, 14486-14493 (2006)

35. L. Frederick, X.Y. Wang, G. Eley \& C.D. James: Diversity and frequency of epidermal growth factor receptor mutations in human glioblastomas. Cancer Res 60, 1383-1387 (2000)

36. J.C. Lee, S.T. Wang, N.H. Chow \& H.B. Yang: Investigation of the prognostic value of coexpressed erbB family members for the survival of colorectal cancer patients after curative surgery. Eur J Cancer 38, 10651071 (2002)

37. N. Shinojima, K. Tada, S. Shiraishi, T. Kamiryo, M. Kochi, H. Nakamura, K. Makino, H. Saya, H. Hirano, J. Kuratsu, K. Oka, Y. Ishimaru \& Y. Ushio: Prognostic value of epidermal growth factor receptor in patients with glioblastoma multiforme. Cancer Res 63, 6962-6970 (2003)

38. J.W. Lee, Y.H. Soung, S.Y. Kim, H.K. Nam, W.S. Park, S.W. Nam, M.S. Kim, D.I. Sun, Y.S. Lee, J.J. Jang, J.Y. Lee, N.J. Yoo \& S.H. Lee: Somatic mutations of EGFR gene in squamous cell carcinoma of the head and neck. Clin. Cancer Res 11, 2879-2882 (2005)

39 I. Fantozzi, D. Grall, S. Cagnol, F. Stanchi, A. Sudaka, M.C. Brunstein, A. Bozec, J.L. Fischel, G. Milano \& E. Van Obberghen-Schilling: Overexpression of cortactin in head and neck squamous cell carcinomas can be uncoupled from augmented EGF receptor expression. Acta Oncol 47, 1502-12 (2008)
40. R. Bhargava, W.L. Gerald, A.R. Li, Q. Pan, P. Lal, M. Ladanyi \& B. Chen: EGFR gene amplification in breast cancer: correlation with epidermal growth factor receptor mRNA and protein expression and HER-2 status and absence of EGFR-activating mutations. Mod Pathol 18, 1027-1033 (2005)

41. M.P. DiGiovanna, D.F. Stern, S.M. Edgerton, S.G. Whalen, D. Moore \& A.D. Thor: Relationship of epidermal growth factor receptor expression to ErbB-2 signaling activity and prognosis in breast cancer patients. J Clin. Oncol 23, 1152-1160 (2005)

42. M. Moroni, S. Veronese, S. Benvenuti, G. Marrapese, A. Sartore-Bianchi, F. Di Nicolantonio, M. Gambacorta, S. Siena \& A. Bardelli: Gene copy number for epidermal growth factor receptor (EGFR) and clinical response to antiEGFR treatment in colorectal cancer: a cohort study. Lancet Oncol 6, 279-286 (2005)

43. G.M. Tse, P.C. Lui, J.S. Vong, K.M. Lau, T.C. Putti, R. Karim, R.A. Scolyer, C.S. Lee, A.M. Yu, D.C. Ng, A.K. Tse \& P.H. Tan: Increased epidermal growth factor receptor (EGFR) expression in malignant mammary phyllodes tumors. Breast Cancer Res Treat 114, 441-8 (2009)

44. C. Kersting, K. Agelopoulos, H. Schmidt, E. Korsching, C. August, G. Gosheger, U. Dirksen, H. Juergens, W. Winkelmann, B. Brandt, S. Bielack, H. Buerger \& C. Gebert. Biological importance of a polymorphic CA sequence within intron 1 of the epidermal growth factor receptor gene (EGFR) in high grade central osteosarcomas. Genes Chromosomes Cancer 47, 657- 64 (2008)

45. S. Ueda, S. Ogata, H. Tsuda, N. Kawarabayashi, M. Kimura, Y. Sugiura, S. Tamai, O. Matsubara, K. Hatsuse \& H. Mochizuki: The correlation between cytoplasmic overexpression of epidermal growth factor receptor and tumor aggressiveness: poor prognosis in patients with pancreatic ductal adenocarcinoma. Pancreas 29, e1- 8 (2004)

46. C.W. Tzeng, A. Frolov, N. Frolova, N.C. Jhala, J.H. Howard, S.M. Vickers, D.J. Buchsbaum, M.J. Heslin \& J.P. Arnoletti: Pancreatic cancer epidermal growth factor receptor (EGFR) intron 1 polymorphism influences postoperative patient survival and in vitro erlotinib response. Ann Surg Oncol 14, 2150-8 (2007)

47. S. Kobayashi, T.J. Boggon, T. Dayaram, P.A. Janne, O. Kocher, M. Meyerson, B.E. Johnson, M.J. Eck, D.G. Tenen $\&$ B. Halmos: EGFR mutation and resistance of non-smallcell lung cancer to gefitinib. $N$ Engl J Med 352, 786-792 (2005)

48. T. Mitsudomi, T. Kosaka, H. Endoh, Y. Horio, T. Hida, S. Mori, S. Hatooka, M. Shinoda, T. Takahashi \& Y. Yatabe: Mutations of the epidermal growth factor receptor gene predict prolonged survival after gefitinib treatment in 
patients with non-small-cell lung cancer with postoperative recurrence. J Clin Oncol 23, 2513-2520 (2005)

49. N.H. Chow, S.H. Chan, T.S. Tzai, C.L. Ho \& H.S. Liu: Expression profiles of ErbB family receptors and prognosis in primary transitional cell carcinoma of the urinary bladder. Clin Cancer Res 7, 1957-1962 (2001)

50. F.R. Hirsch, M. Varella-Garcia, P. A. Bunn, M.V. Di Maria, R. Veve, R.M. Bremmes, A. E. Baron, C. Zeng \& W.A. Franklin: Epidermal growth factor receptor in nonsmall-cell lung carcinomas: correlation between gene copy number and protein expression and impact on prognosis. $J$ Clin Oncol 21, 3798-3807 (2003)

51. T.Y. Chou, C.H. Chiu, L.H. Li, C.Y. Hsiao, C.Y. Tzen, K.T. Chang, Y.M. Chen, R.P. Perng \& S. F. Tsai: Mutation in the tyrosine kinase domain of epidermal growth factor receptor is a predictive and prognostic factor for gefitinib treatment in patients with non-small cell lung cancer. Clin Cancer Res 11, 3750-3757 (2005)

52. A. Hirata, F. Hosoi, M. Miyagawa, S. Ueda, S. Naito, T. Fujii, M. Kuwano \& M. Ono: HER2 overexpression increases sensitivity to gefitinib, an epidermal growth factor receptor tyrosine kinase inhibitor, through inhibition of HER2/HER3 heterodimer formation in lung cancer cells. Cancer Res 65, 4253-4260 (2005)

53. A. Franovic, L. Gunaratnam, K. Smith, I. Robert, D. Patten \& S. Lee: Translational up-regulation of the EGFR by tumor hypoxia provides a nonmutational explanation for its overexpression in human cancer. Proc Natl Acad Sci USA 104, 13092-13097 (2007)

54. K. Okuda, H. Sasaki, O. Kawano, H. Yukiue, T. Yokoyama, M. Yano \& Y. Fujii: Epidermal growth factor receptor gene mutation, amplification and protein expression in malignant pleural mesothelioma. $J$ Cancer Res Clin Oncol 134, 1105-11 (2008)

55. A. Marchetti, C. Martella, L. Felicioni, F. Barassi, S. Salvatore, A. Chella, P.P. Camplese, T. Iarussi, F. Mucilli, A. Mezzetti, F. Cuccurullo, R. Sacco \& F. Buttitta: EGFR mutations in non-small-cell lung cancer: analysis of a large series of cases and development of a rapid and sensitive method for diagnostic screening with potential implications on pharmacologic treatment. J Clin Oncol 23, 857-865 (2005)

56. J. Vermeij, E. Teugels, C. Bourgain, J. Xiangming, P. in 't Veld, V. Ghislain, B. Neyns \& J. De Greve: Genomic activation of the EGFR and HER2-neu genes in a significant proportion of invasive epithelial ovarian cancers. BMC Cancer 8: 3 (2008)

57. Z. Yuan, J. Shin, A. Wilson, S. Goel, Y.H. Ling, N. Ahmed, H. Dopeso, M. Jhawer, S. Nasser, C. Montagna, K. Fordyce, L.H. Augenlicht, L.A. Aaltonen, D. Arango, T.K. Weber \& J.M. Mariadason: An A13 repeat within the 3'untranslated region of epidermal growth factor receptor (EGFR) is frequently mutated in microsatellite instability colon cancers and is associated with increased EGFR expression. Cancer Res 69, 7811-8 (2009)

58. R. Del Sordo, F. Angiero, G. Bellezza, A. Cavaliere, M.G. Mameli, M. Stefani, E. Dessy \& A. Sidoni: HER family receptors expression in squamous cell carcinoma of the tongue: study of the possible prognostic and biological significance. J Oral Pathol Med 39, 79-86 (2010)

59. A. Onn, A.M. Correa, M. Gilcrease, T. Isobe, E. Massarelli, C.D. Bucane, M.S. O'Reilly, W. K. Hong, I.J. Fidler, J. B. Putnam \& R.S. Herbst: Synchronous overexpression of epidermal growth factor receptor and HER2-neu protein is a predictor of poor outcome in patients with stage I non-small cell lung cancer. Clin Cancer Res 10, 136-43 (2004)

60. H. Nagahara, K. Mimori, M. Ohta, T. Utsunomiya, H. Inoue, G.F. Barnard, M. Ohira, K. Hirakawa \& M. Mori: Somatic mutations of epidermal growth factor receptor in colorectal carcinoma. Clin Cancer Res 11, 1368-1371 (2005)

61. S.W. Han, T.Y. Kim, P. G. Hwang, S. Jeong, J. Kim, I.S. Choi, D.Y. Oh, J.H. Kim, D.W. Kim, D.H. Chung, S.A. Im, Y.T. Kim, J.S. Lee, D.S. Heo, Y.J. Bang \& N.K. Kim: Predictive and prognostic impact of epidermal growth factor receptor mutation in non-small-cell lung cancer patients treated with gefitinib. J Clin Oncol 23, 2493-2501 (2005)

62. G. Sartori, A. Cavazza, F. Bertolini, L. Longo, A. Marchioni, M. Costantini, F. Barbieri, M. Migaldi \& G. Rossi: A subset of lung adenocarcinomas and atypical adenomatous hyperplasia-associated foci are genotypically related: an EGFR, HER2, and K-ras mutational analysis. Am J Clin Pathol 129, 202-10 (2008)

63. Y. Sakuma, S. Matsukuma, M. Yoshihara, Y. Nakamura, H. Nakayama, Y. Kameda, E. Tsuchiya \& Y. Miyagi: Epidermal growth factor receptor gene mutations in atypical adenomatous hyperplasias of the lung. Mod Pathol 20, 967-73 (2007)

64. J.G. Paez, P.A. Janne, J.C. Lee, S. Tracy, H. Greulich, S. Gabriel, P. Herman, F.J. Kaye, N. Lindeman, T.J. Boggon, K. Naoki, H. Sasaki, Y. Fujii, M. J. Eck, W.R. Sellers, B.E. Johnson \& M. Meyerson: EGFR mutations in lung cancer: correlation with clinical response to gefitinib therapy. Science 304, 1497-1500 (2004)

65. D.W. Bell, B.W. Brannigan, K. Matsuo, D.M. Finkelstein, R. Sordella, J. Settleman, T. Mitsudomi \& D.A. Haber: Increased prevalence of EGFR-mutant lung cancer in women and in East Asian populations: analysis of estrogen-related polymorphisms. Clin Cancer Res 14, 4079-84 (2008)

66. H. Sasaki, K. Endo, A. Konishi, M. Takada, M. Kawahara, K. Iuchi, A. Matsumura, M. Okumura, H. Tanaka, T. Kawaguchi, T. Shimizu, H. Takeuchi, M. Yano, I. Fukai \& Y. Fujii: EGFR Mutation status in Japanese lung 
cancerpatients: genotyping analysis using LightCycler. Clin Cancer Res 11, 2924-9 (2005)

67. M. Li, L. Liu, Z. Liu, S. Yue, L. Zhou, Q. Zhang, S. Cheng, R. W. Li, P.N. Smith \& S. Lu: The status of KRAS mutations in patients with non-small cell lung cancers from mainland China. Oncol Rep 22, 1013-20 (2009)

68. R.S. Leidner, P. Fu, B. Clifford, A. Hamdan, C. Jin, R. Eisenberg, T.J. Boggon, M. Skokan, W.A. Franklin, F. Cappuzzo, F.R. Hirsch, M. Varella-Garcia \& B. Halmos: Genetic abnormalities of the EGFR pathway in African American Patients with non-small-cell lung cancer. J Clin Oncol 27, 5620-6 (2009)

69. S. Krishnaswamy, R. Kanteti, J.S. Duke-Cohan, S. Loganathan, W. Liu, P.C. Ma, M. Sattler, P.A. Singleton, N. Ramnath, F. Innocenti, D.L. Nicolae, Z. Ouyang, J. Liang, J. Minna, M.F. Kozloff, M.K. Ferguson, V. Natarajan, Y.C. Wang, J.G. Garcia, E.E. Vokes \& R. Salgia: Ethnic differences and functional analysis of MET mutations in lung cancer. Clin Cancer Res 15, 5714-23 (2009)

70. Y. Fujiwara, K. Kiura, S. Toyooka, N. Takigawa, M. Tokumo, K. Hotta, M. Aoe, M. Tabata, K. Matsuo, H. Date \& M. Tanimoto: Relationship between epidermal growth factor receptor gene mutations and the severity of adverse events by gefitinib in patients with advanced non-small cell lung cancer. Lung Cancer 52, 99-103 (2006)

71. T. Kosaka, Y. Yatabe, H. Endoh, H. Kuwano, T. Takahashi \& T. Mitsudomi: Mutations of the epidermal growth factor receptor gene in lung cancer: biological and clinical implications. Cancer Res 64, 8919-23 (2004)

72. H. Sasaki, K. Endo, M. Takada, M. Kawahara, N. Kitahara, H. Tanaka, M. Okumura, A. Matsumura, K. Iuchi, T. Kawaguchi, O. Kawano, H. Yukiue, T. Yokoyama, M. Yano \& Y. Fujii: EGFR exon 20 insertion mutation in Japanese lung cancer. Lung Cancer 58, 324-8 (2007)

73. Y.L. Zhao, Q. Li, X.H. Li, W.D. Han, H.J. Hao, Y.L. Si \& Z.Q. Wu: [Epidermal growth factor receptor mutation in non-small cell lung cancer and breast cancer]. Yi Chuan 29, 547-53 (2007)

74. H. Nakano, H. Soda, Y. Nakamura, K. Uchida, M. Takasu, K. Nakatomi, K. Izumikawa, T. Hayashi, T. Nagayasu, K. Tsukamoto \& S. Kohno: Different epidermal growth factor receptor gene mutations in a patient with 2 synchronous lung cancers. Clin Lung Cancer 8, 562-4 (2007)

75. G.J. Riely, W. Pao, D.K. Pham, A.R. Li, Rizvi N, E.S. Venkatraman, M.F. Zakowski, M.G. Kris, M. Ladanyi \& V.A. Miller: Clinical course of patients with non-small cell lung cancer and epidermal growth factor receptor exon 19 and exon 21 mutations treated with gefitinib or erlotinib. Clin Cancer Res 12, 839-44 (2006)
76. M. Nagane, F. Coufal, H. Lin, O. Bogler, W.K. Cavenee \& H.J. Huang: A common mutant epidermal growth factor receptor confers enhanced tumorigenicity on human glioblastoma cells by increasing proliferation and reducing apoptosis. Cancer Res 56, 5079-86 (1996)

77. Y. Narita, M. Nagane, K. Mishima, H.J. Huang, F.B. Furnari \& W.K. Cavenee: Mutant epidermal growth factor receptor signalling down-regulates p27 through activation of the phosphatidylinositol 3-kinase/Akt pathway in glioblastomas. Cancer Res 62, 6764-9 (2002)

78. C.D. Andl, T. Mizushima, H. Nakagawa, K. Oyama, H. Harada, K. Chruma, M. Herlyn \& A.K. Rustgi: Epidermal growth factor receptor mediates increased cell proliferation, migration, and aggregation in esophageal keratinocytes in vitro and in vivo. J Biol Chem 278, 1824-1830 (2003)

79. H. Shigematsu, L. Lin, T. Takahashi, M. Nomura, M. Suzuki, I.I. Witsub, K.M. Fong, H. Lee, S. Toyooka, N. Shimizu, T. Fujisawa, Z. Feng, J.A. Roth and J. Herz: Clinical $\&$ biological features associated with epidermal growth factor receptor gene mutation in lung cancers. J Natl Cancer Inst 97, 336-9 (2005)

80. A. Frolov, J.S. Liles, A. V. Kossenkov, C.W. Tzeng, N. Jhala, P. Kulesza, S. Varadarajulu, M. Eloubeidi, M.J. Heslin \& J.P. Arnoletti: Epidermal growth factor receptor (EGFR) intron 1 polymorphism and clinical outcome in pancreatic adenocarcinoma." Am J Surg 200, 398-405 (2010)

81. S.W. Han, D.Y. Oh, S.A. Im, S.R. Park, K.W. Lee, H. S. Song, N.S. Lee, K.H. Lee, I.S. Choi, M.H. Lee, M.A. Kim, W.H. Kim, Y.J. Bang \& T.Y. Kim: Epidermal growth factor receptor intron $1 \mathrm{CA}$ dinucleotide repeat polymorphism and survival of advanced gastric cancer patients treated with cetuximab plus modified FOLFOX6. Cancer Sci 101, 793-9 (2010)

82. J.P. Thiery: Epithelial-mesenchymal transitions in development and pathologies. Curr Opin Cell Biol. 15,740-746 (2003)

83. J.P. Thiery: Epithelial-mesenchymal transitions in tumour progression. Nat Rev Cancer 2, $442-454$ (2002)

84. A. Moustakas \& C.H. Heldin: Signaling networks guiding epithelial-mesenchymal transitions during embryogenesis and cancer progression. Cancer Sci 98, 1512-1520 (2007)

85. M. Zeisberg \& E.G. Neilson: Biomarkers for epithelialmesenchymal transitions. J Clin Invest 119, 1429-1437 (2009)

86. H. Peinado, F. Portillo \& A. Cano: Transcriptional regulation of cadherins during development and carcinogenesis. Int J Dev Biol 48, 365-375 (2004)

87. H. Acloque, M.S. Adams, K. Fishwick, M. BronnerFraser \& M.A. Nieto: Epithelial-mesenchymal transitions: 
the importance of changing cell state in development and disease. J Clin Invest 119, 1438-1449 (2009)

88. J.M. Lee, S. Dedhar, R. Kalluri \& E.W. Thompson: The epithelial mesenchymal transition: new insights in signaling, development, and disease. J Cell Biol 172, 973981 (2006)

89. S. Barr, S. Thomson, E. Buck, S. Russo, F. Petti, I. Sujka-Kwok, A. Eyzaguirre, M. Rosenfeld-Franklin, N.W. Gibson, M. Miglarese, D. Epstein, K.K. Iwata \& J.D. Haley: Bypassing cellular EGF receptor dependence through epithelial-to-mesenchymal-like transitions. Clin Exp Metastasis 25, 685-693 (2008)

90. H.J. Hugo, R. Wafai, T. Blick, E.W. Thompson \& D.F. Newgreen: Staurosporine augments EGF-mediated EMT in PMC42-LA cells through actin depolymerisation, focal contact size reduction and Snaill induction - a model for cross-modulation. BMC Cancer 9, 235-250 (2009)

91. H.W. Lo, S.C. Hsu, W. Xia, X. Cao, J.Y. Shih \& Y. Wei: Epidermal growth factor receptor cooperates with signal trans-ducer and activator of transcription 3 to induce epithelial-mesenchymal transition in cancer cells via upregulation of TWIST gene expression. Cancer Res 67, 9066-9076 (2007)

92. G. Christofori \& H. Semb: The role of the cell-adhesion molecule E-cadherin as a tumour-suppressor gene. Trends Biochem Sci 24, 73-76 (1999)

93. L. Strizzi, C. Bianco, N. Normanno, M. Seno, C. Wechselberger \& B. Wallace-Jones: Epithelial mesenchymal transition is a characteristic of hyperplasias and tumors in mammary gland from MMTV-Cripto-1 transgenic mice. J Cell Physiol 201, 266-276 (2004)

94. A.D. Ebert, C. Wechselberger, M. Nees, T. Clair, G. Schaller, I. Martinez-Lacaci, B. Wallace-Jones, C. Bianc, H.K. Weitzel \& D.S. Salomon: Cripto-1-induced increase in vimentin expression is associated with enhanced migration of human Caski cervical carcinoma cells._Exp Cell Res 257, 223-229 ( 2000)

95. Y.P. Gong, P.M Yarrow, H.L. Carmalt, S.Y. Kwun, C.W. Kennedy \& B.P.C. Lin: Overexpression of Cripto and its prognostic significance in breast cancer: a study with long-term survival. Eur J Surg Oncol 33, 438-443 (2007)

96. C. Bianco, L. Strizzi, M. Mancino, A. Rehman, S. Hamada, K. Watanabe, A. De Luca, B. Jones, G. Balogh, J. Russo, D. Mailo, R. Palaia, G. D'Aiuto, G. Botti, F. Perrone, D. S. Salomon \& N. Normanno: Identification of cripto-1 as a novel serologic marker for breast and colon cancer. Clin Cancer Res 12, 5158-5164 ( 2006)

97. D. Liu, C. Huang, K. Kameyama, E. Hayashi, A. Yamauchi, S. Kobayashi \& H. Yokomise: E-cadherin expression associated with differentiation and prognosis in patients with non-small cell lung cancer. Ann Thorac Surg 71, 949-51 (2001)
98. M. Dohadwala, S.C. Yang, J. Luo, S. Sharma, R.K. Batra \& M. Huang: Cyclooxygenase-2-dependent regulation of E-cadherin: prostaglandin $\mathrm{E}(2)$ induces transcriptional repressors ZEB1 and snail in non-small cell lung cancer. Cancer Res 66, 5338-5345 (2006)

99. N.K. Kurrey, K. Amit \& S.A. Bapat: Snail and Slug are major determinants of ovarian cancer invasiveness at the transcription level. Gynecol Oncol 97, 155-165 (2005)

100. T. Imai, A. Horiuchi, C. Wang, K. Oka, S. Ohira, T. Nikaido \& I. Konishi: Hypoxia attenuates the expression of E-cadherin via up-regulation of SNAIL in ovarian carcinoma cells. Am J Pathol 163, 1437-1447 (2003)

101. J.X. Ding, Y.J. Feng, L.Q. Yao, M. Yu, H.Y. Jin \& L.H. Yin: The reinforcement of invasion in epithelial ovarian cancer cells by 17 beta-Estradiol is associated with up-regulation of Snail. Gynecol Oncol 103, 623-630 (2006)

102. M.T. Nieman, R. S. Prudoff, K.R. Johnson \& M.J. Wheelock: N-cadherin promotes motility in human breast cancer cells regardless of their E-cadherin expression. $J$ Cell Biol 147, 631-644 (1999)

103. R. Fodde \& T. Brabletz: Wnt/beta-catenin signaling in cancer stemness and malignant behavior. Curr Opin Cell Bio 9, 150-158 (2007)

104. F. Hlubek, T. Brabletz, J. Budczies, S. Pfeiffer, A. Jung \& T. Kirchner: Heterogeneous expression of Wnt/beta-catenin target genes within colorectal cancer. Int J Cancer 121, 1941-1948 (2007)

105. N. Miyoshi, H. Ishii, K. Mimori, M. Sekimoto, Y. Doki \& M. Mori: TDGF1 is a novel predictive marker for metachronous metastasis of colorectal cancer. Int $J$ Oncol $36,563-568$ (2010)

106. M. Jungck, F. Grunhage, U. Spengler, A. Dernac, M. Mathiak , R. Caspari, W. Friedl \& T. Sauerbruch: Ecadherin expression is homogeneously reduced in adenoma from patients with familial adenomatous polyposis: an immunohistochemical study of E-cadherin, beta-catenin and cyclooxygenase- 2 expression. Int $J$ Colorectal Dis $19,438-445$ (2004)

107. Z. Lu, S. Ghosh, Z. Wang \& T. Hunter: Downregulation of caveolin-1 function by EGF leads to the loss of E-cadherin, increased transcriptional activity of beta-catenin, and enhanced tumor cell invasion. Cancer Cell 4, 499-515 (2003)

108. C.M. Wells, T. Ahmed, J.R. Masters \& G.E. Jones: Rho family GTPases are activated during HGF-stimulated prostate cancer-cell scattering. Cell Motil Cytoskeleton 62, 180-194 (2005)

109. C.C. Yates, C.R. Shepard, D.B. Stolz \& A. Wells: Coculturing human prostate carcinoma cells with hepatocytes leads to increased expression of E-cadherin. $\mathrm{Br} J$ Cancer 96, 1246-1252 (2007) 
110. N.R. Alexander, N.L. Tran, H. Rekapally, C.E. Summers, C. Glackin \& R.L. Heimark: N-cadherin gene expression in prostate carcinoma is modulated by integrindependent nuclear translocation of Twist1. Cancer Res 66, 3365-3369 (2006)

111. W.K. Kwok, M.T. Ling, T.W. Lee, T.C. Lau, C. Zhou, X. Zhang, K.W. Chan, F.L. Chan, C. Glackin, Y.C. Wong \& X. Wang: Up-regulation of TWIST in prostate cancer and its implication as a therapeutic target. Cancer Res 65, 5153-5162 (2005)

112. X. Gu, L.F. Zerbini, H.H. Otu, M. Bhasin, Q. Yang, M.G. Joseph, F. Grall, T. Onatunde, R.G. Correa \& T.A. Libermann: Reduced PDEF expression increases invasion and expression of mesenchymal genes in prostate cancer cells. Cancer Res 67, 4219-4226 (2007)

113. T.L. Veveris-Lowe, M.G. Lawrence, R.L. Collard, L. Bui, A.C. Herington, D. L. Nicol \& J.A. Clements: Kallikrein 4 (hK4) and prostate-specific antigen (PSA) are associated with the loss of E-cadherin and an epithelialmesenchymal transition (EMT)-like effect in prostate cancer cells. Endocr Relat Cancer 12, 631-643 (2005)

114. A.K. Whitbread, T.L. Veveris-Lowe, M.G. Lawrence, D.L. Nicol \& J.A. Clements: The role of kallikrein-related peptidases in prostate cancer: Potential involvement in an epithelial to mesenchymal transition. Biol Chem 387, 707714 (2006)

115. A. Singh \& J. Settleman: EMT, cancer stem cells and drug resistance: an emerging axis of evil in the war on cancer. Oncogene 29, 4741-4751 (2010)

116. L. Yauch, T. Januario, D.A. Eberhard, G. Cavet, W. Zhu, L. Fu, T.Q. Pham, R. Soriano, J. Stinson, S. Seshagiri, Z. Modrusan, C.Y. Lin, V. O'Neill \& L.C. Amler: Epithelial versus mesenchymal phenotype determines in vitro sensitivity and predicts clinical activity of erlotinib in lung cancer patients. Clin. Cancer Res 11, 8686-8698 (2005)

117. S. Thomson, E. Buck, F. Petti, G. Griffin, E. Brown, N. Ramnarine, K.K. Iwata, N. Gibson \& J.D. Haley: Epithelial to mesenchymal transition is a determinant of sensitivity of non-small-cell lung carcinoma cell lines and xenografts to epidermal growth factor receptor inhibition. Cancer Res 65, 9455-9462 (2005)

118. B.A. Frederick, B.A. Helfrich, C.D. Coldren, D. Zheng, D. Chan, P.A. Jr. Bunn \& D. Raben: Epithelial to mesenchymal transition predicts gefitinib resistance in cell lines of head and neck squamous cell carcinoma and nonsmall cell lung carcinoma. Mol. Cancer Ther 6, 16831691(2007)

119. B.C. Fuchs, T. Fujii, J.D. Dorfman, J.M. Goodwin, A.X. Zhu, M. Lanuti \& K.K. Tanabe: Epithelial-tomesenchymal transition and integrin-linked kinase mediate sensitivity to epidermal growth factor receptor inhibition in human hepatoma cells. Cancer Res 68, 2391-2399(2008)
120. A.N. Shah, J.M. Summy, J. Zhang, S.I. Park, N.U. Parikh \& G.E. Gallick: Development and characterization of gemcitabine-resistant pancreatic tumor cells. Ann Surg Oncol 14, 3629-3637 (2007)

121. A.D. Yang, F. Fan, E.R. Camp, B.G. van, W. Liu, R. Somcio, M.J. Gray, H. Cheng, P.M. Hoff \& L.M. Ellis: Chronic oxaliplatin resistance induces epithelialto-mesenchymal transition in colorectal cancer cell lines. Clin. Cancer Res 12, 4147-4153 (2006)

122. J.W. Jung, S.Y. Hwang, J.S. Hwang, E.S. Oh, S. Park \& I.O. Han: Ionising radiation induces changes associated with epithelial-mesenchymal transdifferentiation and increased cell motility of A549 lung epithelial cells. Eur J Cancer 43, 1214-1224 (2007)

123. G.E. Konecny, N. Venkatesan, G. Yang, J. Dering, C. Ginther, R. Finn, M. Rahmeh, M.S. Fejzo, D. Toft, S.W. Jiang, D.J. Slamon \& K.C. Podratz: Activity of lapatinib a novel HER2 and EGFR dual kinase inhibitor in human endometrial cancer cells. $\mathrm{Br} J$ Cancer 98, 1076-1084 (2008)

124. H. Kajiyama, K. Shibata, M. Terauchi, M. Yamashita, K. Ino, A. Nawa \& F. Kikkawa: Chemoresistance to paclitaxel induces epithelialmesenchymal transition and enhances metastatic potential for epithelial ovarian carcinoma cells. Int $J$ Oncol 31, 277-283 (2007)

125. S.A. Mani, W. Guo, M.J. Liao, E. N. Eaton, A. Ayyanan, A.Y. Zhou, M. Brooks, F. Reinhard, C.C. Zhang, M. Shipitsin, L.L. Campbell, K. Polyak, C. Brisken, Yang J \& R.A. Weinberg: The epithelialmesenchymal transition generates cells with properties of stem cells. Cell 133, 704-715 (2008)

126. K. Giehl \& A. Menke: Microenvironmental regulation of E-cadherin-mediated adherens junctions. Front Biosci 13, 3975-85 (2008)

127. P. Friedl \& K. Wolf: Proteolytic and nonproteolytic migration of tumour cells and leucocytes. Biochem Soc Symp 70, 277-85 2003

128. M. Guarino: Epithelial-mesenchymal transition and tumour invasion. Int $J$ Biochem Cell Biol 39, 2153-60 (2007)

129. M. Guarino, B. Rubino \& G. Ballabio: The role of epithelial-mesenchymal transition in cancer pathology. Pathology 39, 305-18 (2007)

130. A-E. Al Moustafa, A. Kassab, A. Darnel \& A. Yasmeen: High-risk HPV/ErbB-2 interaction on Ecadherin/catenin regulation in human carcinogenesis. Curr Pharm Des 14, 2159-72 (2008)

131. A-E. Al Moustafa, C. Yansouni, M.A. AlaouiJamali \& M. O'Connor-McCourt: Up-regulation of Ecadherin by an anti-epidermal growth factor receptor 
monoclonal antibody in lung cancer cell lines. Clin Cancer Res 5, 681-6 (1999a)

132. A-E. Al Moustafa, N. Urbani \& M. O'ConnorMcCourt Black cellular spreading and motility assay. Biotechniques 27, 60-2 (1999b)

133. A-E. Al Moustafa, L. Yen, N. Benlimame \& M.A. Alaoui-Jamali: Regulation of E-cadherin/catenin complex patterns by epidermal growth factor receptor modulation in human lung cancer cells. Lung Cancer 37, 49-56 (2002)

134. M. Kandouz, A. Alachkar, L. Zhang, H. Dekhil, F. Chehna, A. Yasmeen and A-E. Al Moustafa: Teucrium polium plant extract inhibits cell invasion and motility of human prostate cancer cells via the restoration of the Ecadherin/catenin complex. J Ethnopharmacol 129, 410-5. (2010)

135. K. Haïdara, A. Alachkar \& A-E. Al Moustafa: Teucrium polium plant extract provokes significant cell apoptosis in human lung cancer cells. Health Journal, in press.

136. H. Peinado, D. Olmeda and A. Cano: Snail, Zeb and bHLH factors in tumour progression: an alliance against the epithelial phenotype? Nat Rev Cancer 7, 415-28 (2007)

137. J.P. Thiery \& J.P. Sleeman: Complex networks orchestrate epithelial-mesenchymal transitions. Nat Rev Mol Cell Biol 7, 131-42 (2006)

138. M.L. Ackland, D.F. Newgreen, M. Fridman, M.C. Waltham, A. Arvanitis, J. Minichiello, J.T. Price \& E.W. Thompson: Epidermal growth factor-induced epitheliomesenchymal transition in human breast carcinoma cells. Lab Invest 83, 435-48 (2003)

139. C.B. Forsyth, Y. Tang, M. Shaikh, L. Zhang \& A. Keshavarzian: Alcohol stimulates activation of Snail, epidermal growth factor receptor signaling, and biomarkers of epithelial-mesenchymal transition in colon and breast cancer cells. Alcohol Clin Exp Res 34, 19-31 (2010)

140. J.R. Mann, M.G. Backlund, F.G. Buchanan, T. Daikoku, V.R. Holla, D.W. Rosenberg, S.K. Dey \& R.N. DuBois: Repression of prostaglandin dehydrogenase by epidermal growth factor and snail increases prostaglandin E2 and promotes cancer progression. Cancer Res 66, 664956 (2006)

141. M.Y. Lee, C.Y. Chou, M.J. Tang \& M.R. Shen: Epithelial-mesenchymal transition in cervical cancer: correlation with tumor progression, epidermal growth factor receptor overexpression, and snail up-regulation. Clin Cancer Res 14, 4743-50 (2008)

142. T. Goldkorn \& S. Filosto: Lung injury and cancer: Mechanistic insights into ceramide and EGFR signaling under cigarette smoke. Am J Respir Cell Mol Biol 43, 25968 (2010)
143. I. Yoshino, T. Kometani, F. Shoji, A. Osoegawa, T. Ohba, H. Kouso, T. Takenaka, T. Yohena \& Y. Maehara: Induction of epithelial-mesenchymal transition-related genes by benzo[a]pyrene in lung cancer cells. Cancer 110 , 369-74 (2007)

144. S.E. Witta, R.M. Gemmill, F.R. Hirsch, C.D. Coldren, K. Hedman, L. Ravdel, B. Helfrich, R. Dziadziuszko, D.C. Chan, M. Sugita, Z. Chan, A. Baron, W. Franklin, H.A. Drabkin, L. Girard, A.F. Gazdar, J.D. Minna \& P.A. Jr. Bunn: Restoring e-cadherin expression increases sensitivity to epidermal growth factor receptor inhibitors in lung cancer cell lines. Cancer Res 66, 944-950 (2006)

145. F.M. Johnson \& G.E. Gallick: SRC family nonreceptor tyrosine kinases as molecular targets for cancer therapy. Anticancer Agents Med Chem 7, 651-9 (2007)

146. R. Schmidmaier \& P. Baumann: ANTI-ADHESION evolves to a promising therapeutic concept in oncology. Curr Med Chem 15, 978-90 (2008)

147. M.D. Basson: An intracellular signal pathway that regulates cancer cell adhesion in response to extracellular forces. Cancer Res 68, 2-4 (2008)

148. A. Yasmeen, T.A. Bismar, H. Dekhil, R. Ricciardi, A. Kassab, C. Gambacorti-Passerini \& A-E. Al Moustafa: ErbB-2 receptor cooperates with E6/E7 oncoproteins of HPV type 16 in breast tumorigenesis. Cell Cycle 6, 293943 (2007)

149. A. Yasmeen, A. Alachkar, H. Dekhil, C. GambacortiPasserini \& A-E. Al Moustafa: Locking Src/Abl tyrosine kinase activities regulate cell differentiation and invasion of human cervical cancer cells expressing E6/E7 oncoproteins of high-risk HPV. J Oncol in press (2010)

Abbreviations: AR: Amphiregulin; BTC: Betacellulin; CAS: Crk-associated substrate; COX2: Cyclooxygenase-2; E-cadherin: Epithelial-cadherin; ECM: Extracellular matrix; EGF-R: Epidermal growth factor-receptors; EMT: Epithelial-mesenchymal transition; EPR: Epiregulin; ERK: Extracellular signal regulated kinases; ETS: E26 transformation specific; FAK: Focal Adhesion protein; HBEGF: Heparin-binding EGF like growth factor; HNSCC: Head and neck squamous cell carcinomas; JAK: Janus protein tyrosine kinase; KLK: Kallikrein-related peptidase; mAbs: Monoclonal Antibodies; MAPK: Mitogen-activated protein kinases; Met: MNNG HOS Transforming gene; MMP: Matrix metalloproteinase; N-cadherin: Neuralcadherin; NRG: Neuregulin; NSCL: Non-small cell lung cancer; P-cadherin: Placental-cadherin; PDEF: Prostatederived ETS factor; Pge-2: Prostaglandin E2; PI3K: phosphatidylinosital 3-kinase; PKC: Atypical protein kinase C; PLCc: Phospholipase C-c; PLC $\gamma$ : Phopholipase C $\gamma$; PSA: Prostate-specific antigen; RAS: RAt Sarcoma; SRC: Sarcoma; STAT: Signal transducers and activators of transcription; TGF- $\alpha$ : Transforming growth factor- alpha; TGF- $\beta$ : Transforming growth factor- beta; TKIs: Tyrosine kinase inhibitor; TP: Teucrium polium; UV: Ultra-violet 
EGF-R/EMT interaction in human carcinomas

Key Words: EGF-receptor, Epithelial-Mesenchymal Transition, Human Cancer Progression, Review

Send correspondence to: A-E. Al Moustafa, Syrian Research Cancer Centre of the Syrian Society against Cancer, Aleppo, Syria, Tel: 96321 2644246, Fax: 96321 26499150, E-mail: ala-eddin.almoustafa@mcgill.ca

http://www.bioscience.org/current/vol4S.htm 